\title{
A Study on the Influence of Different Constraint Modes and Number of Disc Springs on the Dynamics of Disc Spring System
}

\author{
Jiacheng Zhou (D), Chuzhe Zhang, Ziqiu Wang, Kuanmin Mao $\mathbb{D}$, and Xiaoyu Wang \\ School of Mechanical Science \& Engineering, Huazhong University of Science and Technology, Wuhan 430074, China \\ Correspondence should be addressed to Xiaoyu Wang; xy_wang@hust.edu.cn
}

Received 15 August 2020; Revised 25 January 2021; Accepted 28 February 2021; Published 8 March 2021

Academic Editor: Fabio Minghini

Copyright ( 2021 Jiacheng Zhou et al. This is an open access article distributed under the Creative Commons Attribution License, which permits unrestricted use, distribution, and reproduction in any medium, provided the original work is properly cited.

\begin{abstract}
In this work, the influences of constraint modes and the number of disc springs on the dynamic characteristics of the disc spring system are studied by simulation and experiment. The amplitudes and amplification factors of the disc spring system under different constraint modes and different numbers of disc springs are obtained. The results show that the maximum amplitude and amplification factor both appear at the constraint modes of locking and no preloading, which indicates that the locking and no preloading is the best constraint mode among the four different constraint modes. Moreover, the amplitude of the disc spring system first increases and then decreases with the number of disc springs increasing, while the amplification factor increases with the number of disc springs increasing. The maximum amplification factor (10.21 in experiment) of the disc spring system appears at 10 disc springs. By studying the relationship between the number of disc springs and amplification factor and damping, we find that the damping of the disc spring system can be reduced by increasing the disc spring numbers, and thus, the corresponding amplification factor can be improved. Furthermore, as the number of disc spring increases, the height differences of disc springs before and after locking are all close to $3 \mathrm{~mm}$, which indicates that the amount of locking compression in the assembly process has a good consistency when the number of disc springs changes. The aforementioned works can provide guidance for the industrial production in screen vibration.
\end{abstract}

\section{Introduction}

There are many kinds of vibrating screens: linear vibration screen [1], resonance screen [2], circular vibration screen [3], banana screen [4], and so on. Among them, traditional linear and circle vibration screens are widely used in industry because of their simple structure and reliable operation. At present, the helical spring is the main vibration component in traditional vibration screen [5]. Due to the low stiffness of helical spring, the natural frequency is usually much lower than the resonance frequency in traditional vibration screen [6]. Therefore, the vibration amplitude cannot be amplified by resonance principle. Larger amplitude can only be obtained by larger exciting force in linear and circle vibration screens.

By contrast, relying on the principle of resonance [7], the traditional resonance screen obtains larger amplitude by less exciting force [8]. However, due to the complex structure and use of nonlinear spring [9], the variation of stiffness is large in traditional resonance screen. As a result, the natural frequency of the vibration screen is not a fixed value, which results in the unstable working state of the screen [10].

To avoid large exciting force in traditional linear vibrating screen and unstable working state in resonance screen, a new vibration screen which has a stable working state as well as small exciting force is needed. By using the disc spring system and matching the corresponding natural frequency, the new vibration screen is designed [11]. As we all know, spring is a mechanical vibrator in the vibration screen [12]. Different types of springs have different effects on the dynamic characteristics of vibration screen systems. Thus, different vibrating screens have different working characteristics. Compared with the helical spring in traditional linear vibration screen and nonlinear spring in resonance screen, disc spring has the characteristics of large load bearing capacity, stable working state, long service life, and high stiffness $[13,14]$. Replacing helical spring and nonlinear spring with disc spring, the whole stiffness of 
vibration can be improved, and the natural frequency of vibration screen can be increased.

Consequently, more attention should be paid to the factors affecting the dynamic characteristics of the disc spring system. Meanwhile, in actual working of vibration screen, the constraint has a great influence on stiffness of disc spring system. Different constraints will lead to different stiffness of the spring system $[15,16]$. Due to the variation of stiffness [17], the natural frequency of the vibration screen can change greatly. When the working frequency is far from the natural frequency in vibration screen, the amplitude cannot be amplified by resonance principle. It is harmful to obtain a too large amplitude in vibration screen for the unstable natural frequency. The production and screening efficiency of the vibration screen are directly affected by amplitude [18]. In addition, the foundation produces cracks when vibration screen is working under inappropriate constraints. Therefore, it is of great significance to study the constraint in vibration screen.

At present, the preloading on metal-elastomer torsion spring [19] and optimal design of large vibrating screen based on multiple frequencies constraints [20] have been studied. However, the research about constraint modes of disc spring system in the vibration screen is less. Thus, it is the significance of this study. Moreover, the number of disc springs in single disc spring system is also an important factor affecting vibration in vibration screen. The influence of number and combination of disc spring on the static characteristics of disc spring group has been reported $[21,22]$. However, there are a few studies in effect on the number of disc spring on the dynamic characteristics of the system. Hence, the influence of the number of disc springs on dynamic characteristic in a single disc spring system has also been urgent studied.

In this work, the influence of constraint modes and number of disc springs on dynamic characteristic of disc spring system is researched. The model of the disc spring system in vibration screen is established by both simulation and experiment. First, amplitude and amplification factor under four different constraint modes are studied. Then, the number of disc spring is varied to investigate the effect on dynamic performance. The frequency, amplitude, and amplification factors of the disc spring system in vibration screen under different constraint modes and different number of disc springs are studied. Furthermore, by comparing the amplification factors under different numbers of disc springs, the damping factors under different number of disc springs are discussed.

\section{Methods and Methodology}

2.1. Experimental Model. Figure 1 shows the vibration screen in experiment. The vibration screen is $6.5 \mathrm{~m}$ in length and $4.2 \mathrm{~m}$ in width, which is supported by four disc spring systems at four corners, respectively. Disc spring system is the main vibration component in this vibration screen which is shown in the bottom right corner of Figure 1.

In order to investigate the influence of constraints on the vibration of disc spring system and study the dynamic

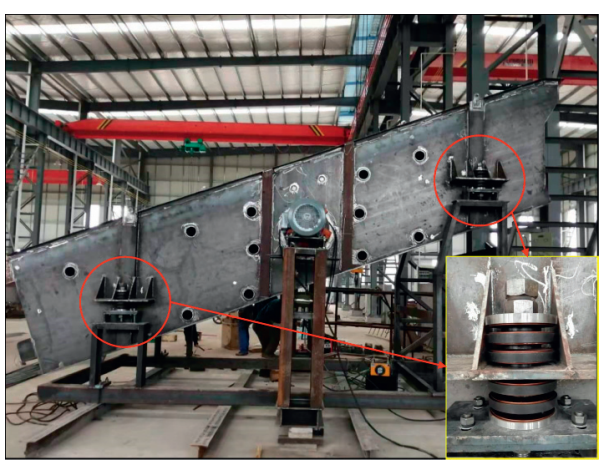

Figure 1: Vibration screen and disc spring system.

characteristics of the disc spring system, the experimental model of the disc spring system is built, shown in Figure 2(a), and the corresponding structural sketch is shown in Figure 2(b).

As shown in Figure 2(b), the whole disc spring assembly is divided into two parts by braced frame. The diameter of the shaft assembled by the disc springs is $120 \mathrm{~mm}$. The constraint of disc spring system will be changed by adjusting the tightness of the large-diameter screw nut. Preloads will be exerted by a large-size torque wrench. The electric motor and eccentric mass are connected to the system by the connecting plate and mass block. The number of disc spring is varied to research the influence of the number of disc springs on dynamic characteristic in disc spring system, which is shown in Figure 2(c).

2.2. Movement Analysis of the Disc Spring System. Figure 3 shows the different movement analyses of the disc spring system under four different constraint modes. The fastening screw nut, baseplate, and support plate of braced frame are represented by rectangle. The polyline and rod represent the disc spring assembly and support the shaft, respectively. The stiffness of the upper and lower disc spring assembly is $k$, respectively.

The four different movements under different constraint modes are analyzed as follows.

(I) No Locking and No Preloading. In this case, the initial state of the disc springs is shown in Figure 3(a)(1). The upper and lower disc spring assemblies are free states. Figures 3(a)(2) and 3(a)(3) show upward and downward movement of the disc spring system, respectively.

When the disc system moves upward, the support plate and the lower disc spring assembly are separated. Both part disc spring assemblies are free under this moving process. The system stiffness $K$ is zero. The disc spring system is only subject to excitation force. $A_{1}$ is the maximum displacement of upward movement. When the system moves downward, the lower disc spring assembly is compressed by support plate, and the upper disc spring assembly remains free. At this moment, the system stiffness $K$ is $k$, which is the stiffness of the lower disc spring assembly. $A_{2}$ is the maximum displacement of downward movement. According to the different positions of support plate in movement, the system stiffness $K$ is as follows: 


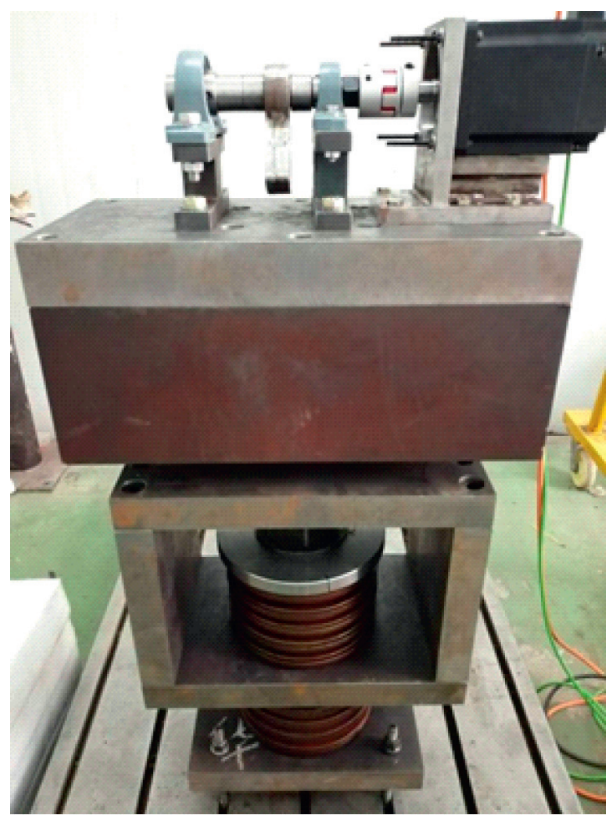

(a)
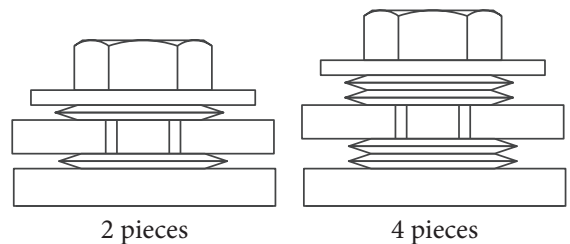

4 pieces

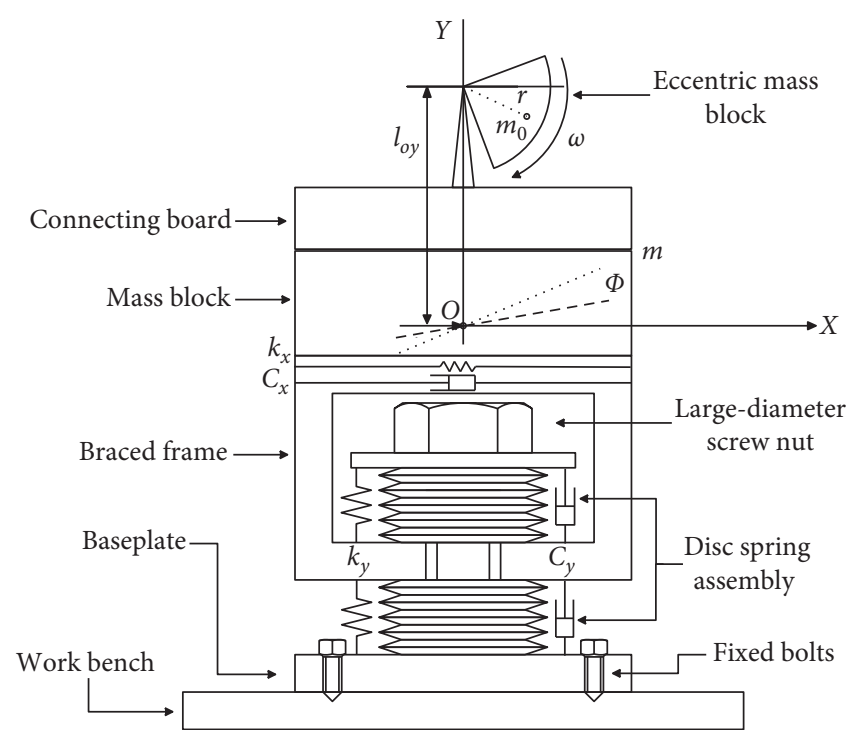

(b)

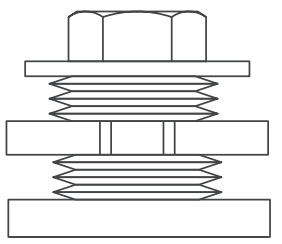

6 pieces

(c)

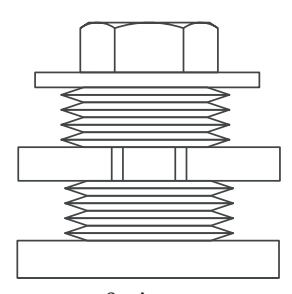

8 pieces

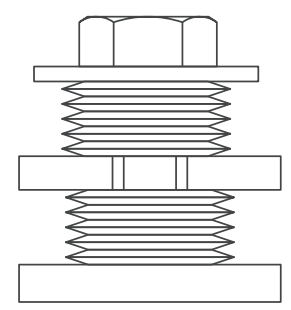

10 pieces

FIGURE 2: Disc spring vibration system: (a) experiment model, (b) structural sketch, and (c) different numbers of disc springs.

$$
K= \begin{cases}0, & \left(0<x<A_{1}\right), \\ k, & -A_{2}<x<0 .\end{cases}
$$

(II) Locking and No Preloading. In this case, the initial state of the disc springs is shown in Figure 3(b)(1). Both part disc spring assemblies are free states. Figures 3(b)(2) and 3(b)(3) show upward and downward movement of the disc spring system, respectively.

When the system moves upward, the support plate and the lower disc spring assembly are separated. The upper disc spring assembly is compressed by support plate, and the lower disc spring assembly remains free. At this moment, the system stiffness $K$ is the stiffness of the upper disc spring assembly $k . A_{1}$ is the maximum displacement of the upward movement. Besides, when the system moves downward, the lower disc spring assembly is compressed by the support plate, and the upper disc spring assembly remains free. At this moment, the system stiffness $K$ is $k$, which is the stiffness of the lower disc spring assembly. $A_{2}$ is the maximum displacement of downward movement. Therefore, the system stiffness $K$ is $k$ in the whole process of movement. The amplitude $A_{1}$ is equal to $A_{2}$.

(III) Locking and Preloading with the Amount of Compression Being Less than Twice the Amplitude $\left(l_{0}<2 A\right)$. F is the preload and $l_{0}$ is the amount of compression by the preload. The $A_{1}$ and $A_{2}$ are the amplitude of system under different movement processes.

In this case, the initial state of the disc springs is shown in Figure 3(c)(1). Both part disc spring assemblies are free states. Figure 3(c)(2) shows the state of the disc spring system under preloading. It can be seen that the upper and lower disc spring assemblies are in the same compression state.

Figures 3(c)(3) and 3(c)(4) show the upward movement of the disc spring system. When the support plate moves from the position in Figure 3(c)(2) to the position in Figure 3(c) (3), the upper and lower disc spring assemblies are both compressed. At this moment, the system stiffness $K$ is $2 k$, which is the sum of the stiffness of the upper and lower disc spring assemblies. The displacement of this movement is $A_{1}$.

When the support plate moves from the position in Figure 3(c) (3) to the position in Figure 3(c)(4), the support plate and lower disc spring assembly are separated. At this moment, the upper disc spring assembly continues to be compressed, and the lower disc spring assembly is free. Therefore, the system stiffness $K$ is $k$, which is the stiffness of the upper disc spring assembly. The displacement of this movement is $A_{0}$. 


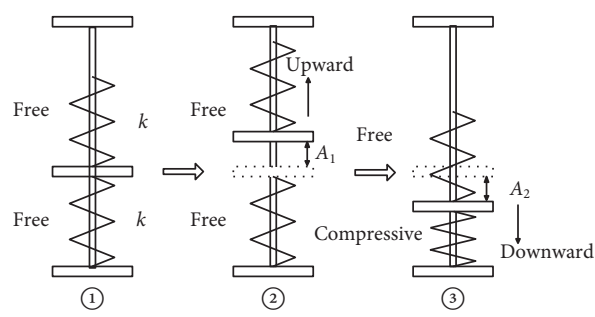

(a)

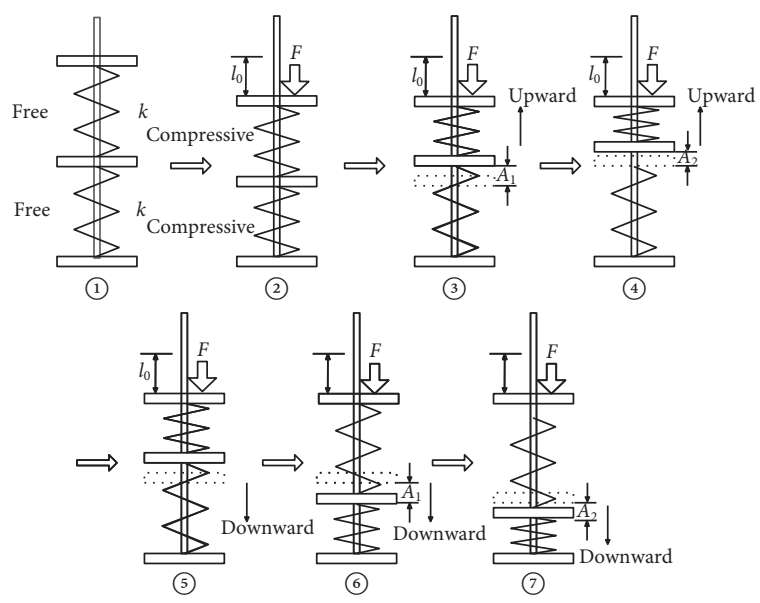

(c)

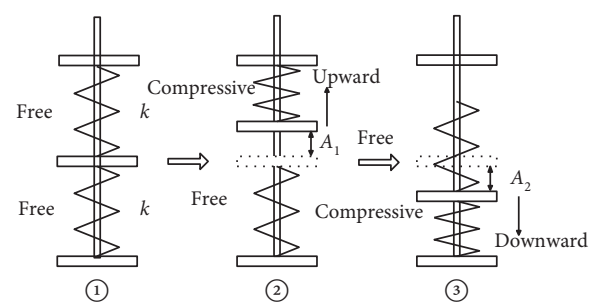

(b)

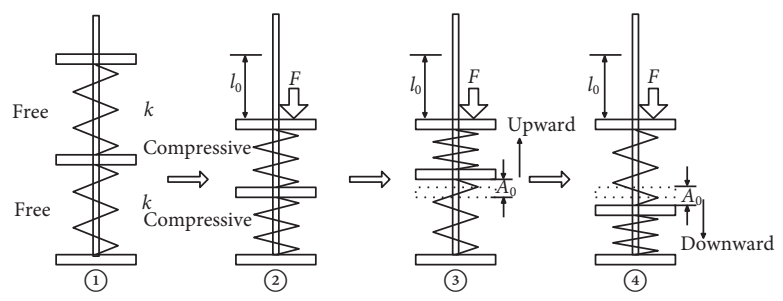

(d)

Figure 3: Movements of the disc spring system under four different constraints: (a) no locking and no preloading, (b) locking and no preloading, (c) locking and preloading $\left(l_{0}<2 A\right)$, and (d) locking and preloading $\left(l_{0}>2 A\right)$.

Figures 3(c) (6) and 3(c) (7) show the downward movement of the disc spring system. When the support plate moves from the position in Figure 3(c)(5) to the position in Figure 3(c)(6), the upper and lower disc spring assemblies are both compressed. At this moment, the system stiffness $K$ is $2 k$, which is the sum of the stiffness of the upper and lower disc spring assemblies. The displacement of this movement is $A_{1}$.

When the support plate moves from the position in Figure 3(c)(6) to the position in Figure 3(c) (7), the support plate and the upper disc spring assembly are separated. At this moment, the lower disc spring assembly continues to be compressed, and the upper disc spring assembly is free. Therefore, the system stiffness $K$ is $k$, which is the stiffness of the lower disc spring assembly. The displacement of this movement is $A_{0}$. According to the different positions of support plate in movement, the system stiffness $K$ is as follows:

$$
K= \begin{cases}2 k, & \left(-A_{1}<x<A_{1}\right), \\ k, & \left(-A_{2}<x<-A_{1}, A_{1}<x<A_{2}\right) .\end{cases}
$$

(IV) Locking and Preloading with the Amount of Compression Being More than Twice the Amplitude $\left(l_{0}>2 A\right)$. In this case, the initial state of the disc springs is shown in Figure 3(d)(1). Both part disc spring assemblies are free states. Figure 3(d)(2) shows the state of the disc spring system under preloading. It can be seen that the upper and lower disc spring assemblies are in the same compression state. Figures 3(d)(3) and 3(d)(4) show the upward and downward movement of the disc spring system, respectively.
When the system moves upward or downward, the upper and lower disc spring assemblies are both compressed. At this moment, the system stiffness $K$ is the stiffness of the upper disc spring assembly $k . A_{1}$ is the maximum displacement of upward movement. In addition, when the system moves downward, the lower disc spring assembly is compressed by the support plate, and the upper disc spring assembly remains free. At this moment, the system stiffness $K$ is $2 k$, which is the sum of the stiffness of the upper and lower disc spring assemblies. Therefore, the system stiffness $K$ is $k$ in the whole process of movement.

\section{Simulation and Experimental Procedure}

Modal analysis is an important method to obtain the dynamic parameters of the research object, which is widely used in the field of architecture and structural engineering [23-26].

3.1. Natural Frequency of the Disc Spring System. According to the theories of the free vibration without damping, the natural frequency $f_{n}$ [27] of the disc spring system is shown in formula (3). $\omega_{n}$ stands for the natural angular frequency of the system, and $k$ refers to the stiffness of the disc spring system:

$$
f_{n}=\frac{\omega_{n}}{2 \pi}=\frac{1}{2 \pi} \sqrt{\frac{k}{m}}
$$


Considering the existence of the damping in the system [28], the actual natural frequency on vertical direction is slightly higher than the frequency of calculation.

3.2. Simulation and Experiment of Modal Analysis. Finite element analysis can simulate the experiment process and shorten the experiment time and cost. The results of simulation can provide the reference for the experiment [29]. Figure 4 shows the meshed finite element model, and Table 1 shows the material parameters of finite element model.

According to the processes of movement analysis of disc spring system, the different constraint modes are applied to the model. The linear contact is adopted between the disc springs while the surface-to-surface contact is adopted to other components. Frictionless is set in two types of contact. In order to prevent large displacement of rigid body, the weak spring setting is enabled. After preprocessing of the model, the block Lanczos algorithm [30] is adopted in the modal simulation.

After the modal analysis in simulation, the experiment is carried out. Figure 5(a) shows the experimental scenarios of modal analysis [31]. The impact test method is obtained in experiment. The impacting excitation which is generated by the hammer is received by four acceleration sensors. Through the postprocessing in modal analysis module (LMS), the natural frequency and mode shape of the disc spring system are obtained.

3.3. Amplitude Simulation and Experiment. The simulation and experiment of amplitude are carried out with different constraint modes and different number of disc springs. By changing the motor speed, the working frequency of disc spring system can be adjusted in experiment [32]. The amplitude simulation is completed in transient analysis module in finite element software [33]. Formula (4) shows the equation of dynamic force of disc spring system:

$$
\begin{aligned}
F & =F_{0} * \sin \left(f * \frac{\pi}{30} *\{\text { Time }\}\right), \\
F_{0} & =(f * 2 \pi)^{2} * m * r
\end{aligned}
$$

$F$ and $F_{0}$ are the dynamic force and centrifugal force produced by eccentric block at specified speed, respectively. Formula (5) is the expression of centrifugal force. $f$ denotes the working frequency in the vibration system. \{Time $\}$ is the time of duration in transient analysis. $m$ and $r$ represent the mass of eccentric block and eccentricity distance, respectively. The full algorithm [34] is adopted in the transient analysis. The damping coefficient of disc spring system is set to be 0.1 [35].

Figure 5(b) shows the experimental scenarios of amplitude. The amplitudes of disc spring system and workbench are recorded by two laser displacement sensor, respectively. The dynamic force is produced by the motor driving the eccentric block. The amplitude data is stored in the signal acquisition module.

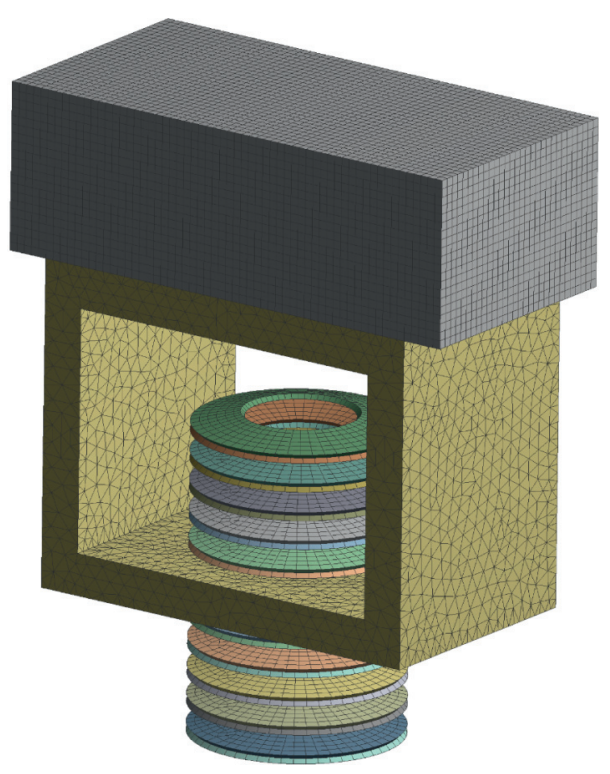

FIGURE 4: Simulation model of the disc spring system.

According to the theory of the force vibration with simple harmonic excitation, amplitude $X$ is proportional to the static displacement $A[36]$ :

$$
\begin{aligned}
X & =|H(\omega)| A, \\
|H(\omega)| & =\frac{1}{\sqrt{\left[1-\left(\omega / \omega_{n}\right)^{2}\right]^{2}+\left(2 \xi \omega / \omega_{n}\right)^{2}}} .
\end{aligned}
$$

Formula (7) is the amplification factor of the disc spring system. The $|H(\omega)|$ is the ratio of amplitude $X$ to static displacement $A$. $\xi$ is the damping factor, and $\omega_{n}$ is the natural angular frequency of the system. $\omega$ stands for the excitation frequency when the system is working. According to formula (7), the amplification factor can be calculated.

\section{Results and Discussion}

4.1. Modal Analysis. Figure 6 shows the third order mode shape of the disc spring system with 10 springs under locking and no preloading. The white wireframe in Figure 6(a) represents the model of the system itself, while the colored wireframe represents the mode shapes of the system at $Z$ direction. The $Z$ direction mode shapes of the disc spring system under other constraints are similar to this mode shape, which will not be repeated again. We found that the disc spring system vibrates in the vertical direction at the third order natural frequency in both the simulation and experiment, which is consistent with the direction of the vibration screen when screening particles. Therefore, dynamic characteristics of the disc spring system at third order natural frequency under different constraints and number of disc springs should be focused.

The third-order natural frequencies of the disc spring system under different constraint modes and different number of disc springs are shown in Figures 7 (a) and $7(\mathrm{~b})$, respectively. Points $A, B, C$, and $D$ in Figure 7 (a) indicate the 
TABLE 1: Material parameters of the finite element model.

\begin{tabular}{lccc}
\hline Material & Density $\left(\mathrm{kg} / \mathrm{m}^{3}\right)$ & Elastic modulus $(\mathrm{G} \mathrm{Pa})$ & Poisson ratio \\
\hline Mass block (gray cast iron) & 7350 & 120 & 0.27 \\
Braced frame (steel) & 7900 & 210 & 0.25 \\
Disc spring (spring steel) & 7810 & 196.5 & 0.28 \\
\hline
\end{tabular}

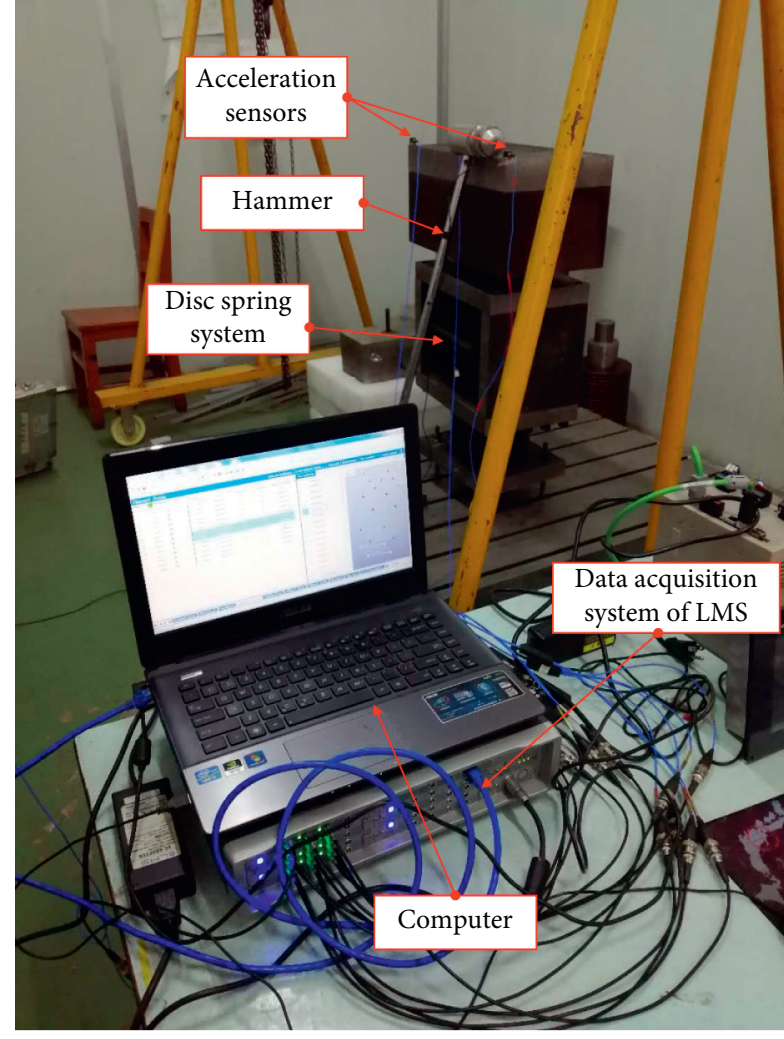

(a)

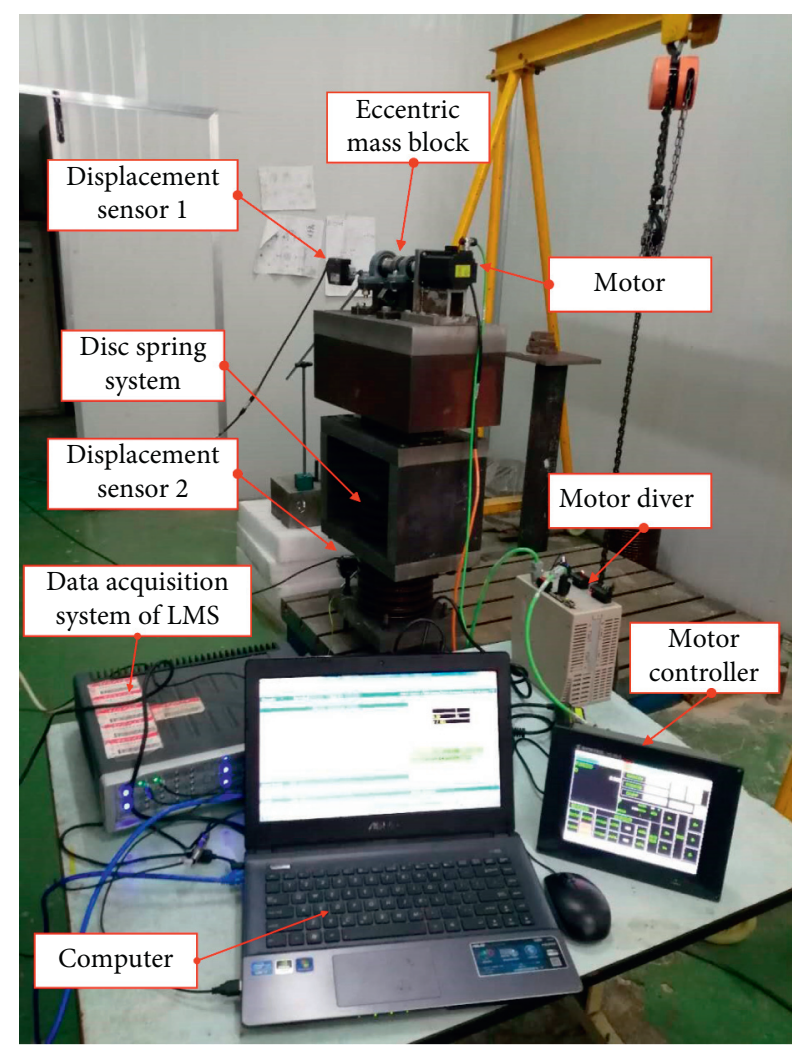

(b)

FIGURE 5: Specific experimental equipment and scenarios: (a) modal test and (b) amplitude test.

four different constraint modes: no locking and no preloading, locking and no preloading, amount of preload compression being less than twice the amplitude, and amount of preload compression being more than twice the amplitude, correspondingly. As the constraint modes change from $A$ to $D$, the natural frequency increases in Figure $7(\mathrm{a})$, which indicates that the stiffness increases with the constraint modes changing from $A$ to $D$. This result is consistent with Wang Wei's conclusion that the preloading displacement has a positive correlation relationship with the equivalent damping ratio and equivalent stiffness of the coned disc spring compound vertical isolation [37].

Meanwhile, the natural frequency decreases with the increase of disc spring numbers in Figure 7(b), which suggests that the stiffness decreases with the increase of disc spring numbers. It can be seen that the trends of the natural frequencies in simulation and experiment are basically the same. It should be noted that the natural frequencies in simulation are slightly larger than that in experiment. It is due to neglecting damping and assembly errors in simulation.
According to the natural frequency in Figure 7 under different constraint modes and different number of disc springs, the following dynamic characteristics of the disc spring system under different conditions are researched at the corresponding natural frequency.

4.2. Effects of Constraint Modes. Figure 8(a) shows the amplitudes of the disc spring system under different constraint modes, while Figure 8 (b) shows the corresponding amplification factors of disc spring system. Points $A, B, C$, and $D$ represent the four different constraint modes which are same as that in Figure $7(\mathrm{a})$.

It can be seen that the maximum amplitude of the disc spring system appears at constraint mode of locking and no preloading in both simulation and experiment. The maximum amplitude of the disc spring system is $2.07 \mathrm{~mm}$ in experiment. Meanwhile, the maximum amplification factor of disc spring system also appears at the constraint mode of locking and no preloading in both simulation and experiment. The maximum amplification factor of disc spring 


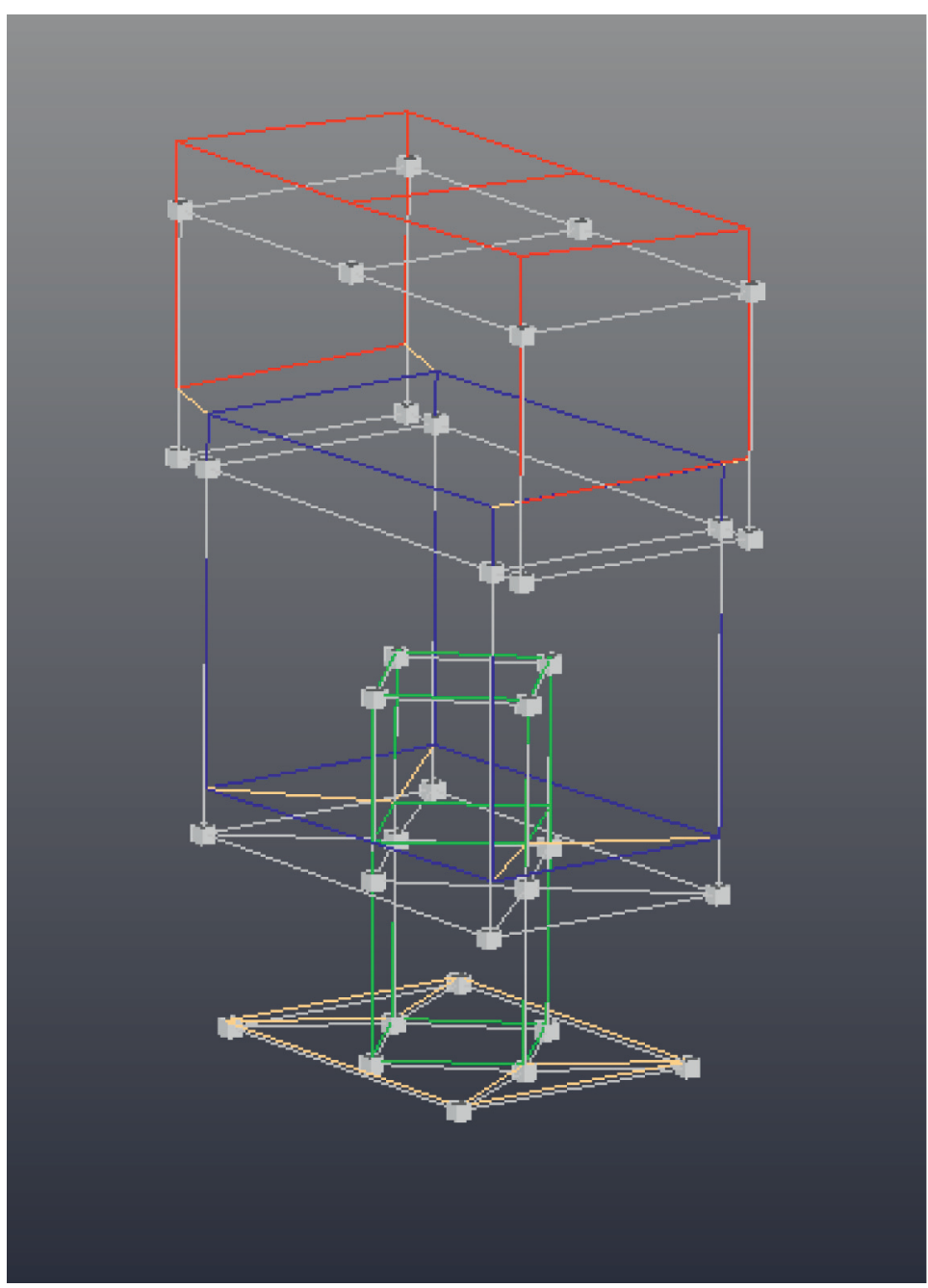

(a)

Figure 6: Continued. 


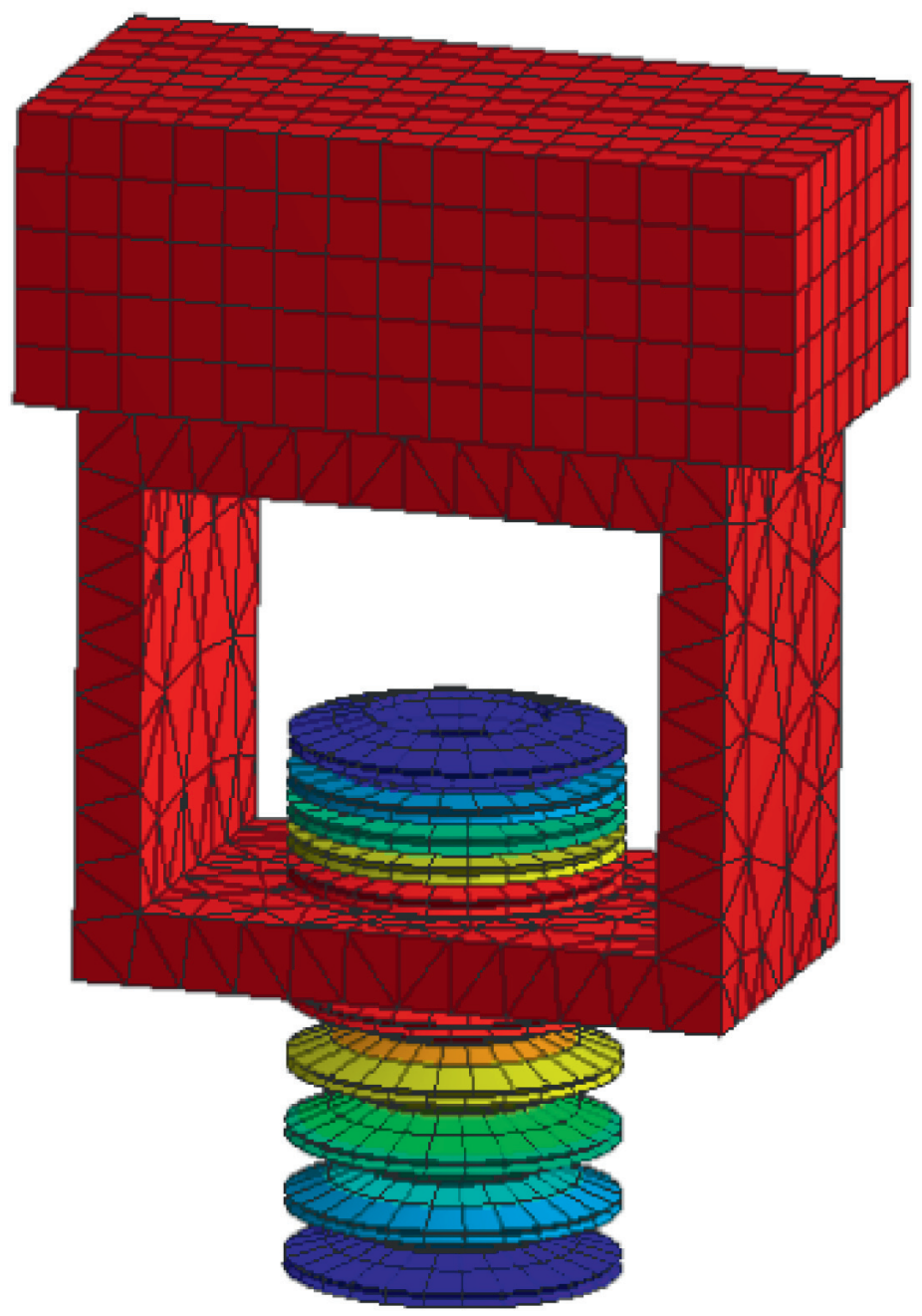

(b)

FIGURE 6: Third-order mode shapes of the disc spring system with 10 springs under locking and no preloading: (a) experiment and (b) simulation.

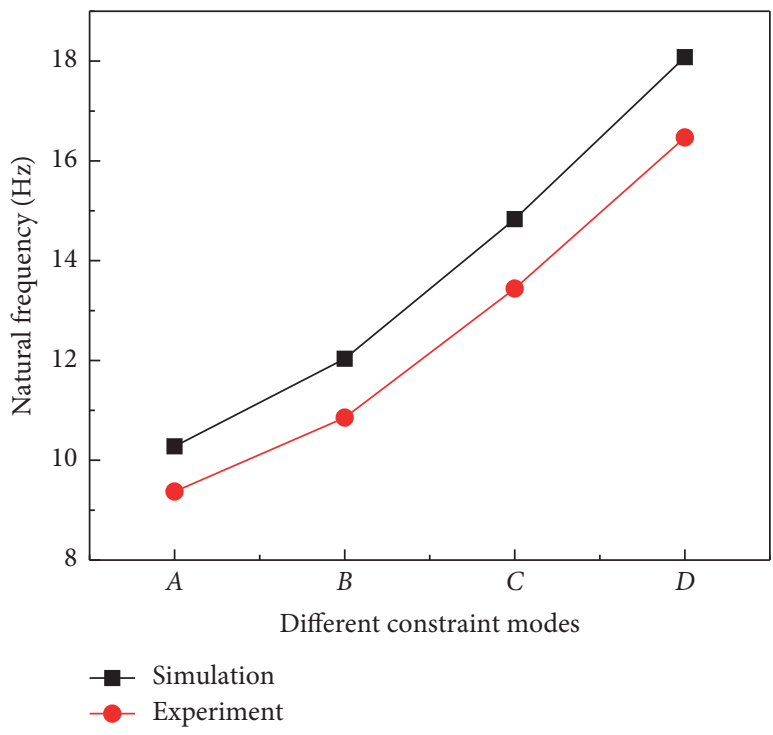

(a)

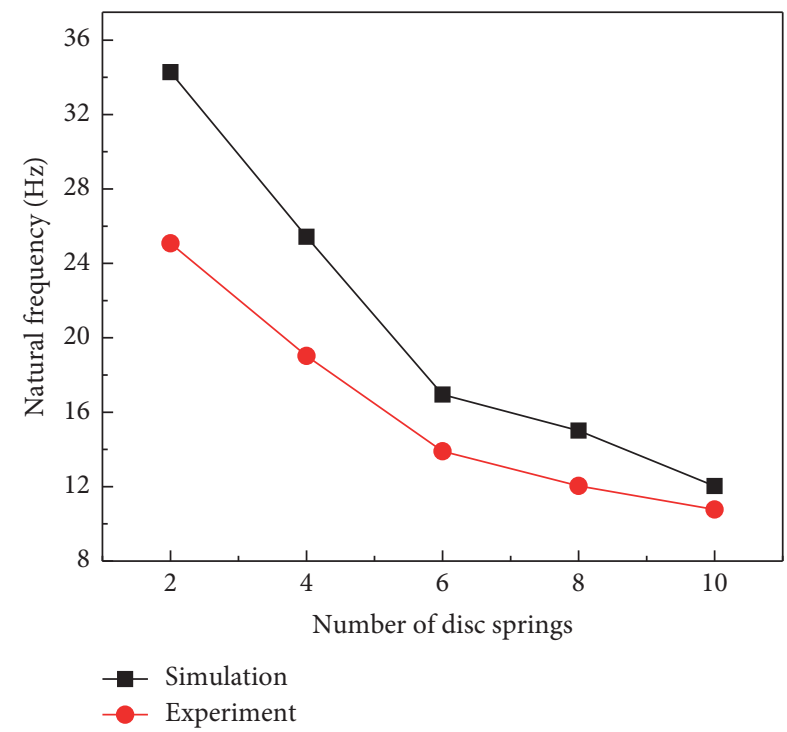

(b)

Figure 7: Natural frequency of disc spring system under (a) four different constraint modes and (b) different number of disc springs. $A, B, C$, and $D$ refer to no locking and no preloading, locking and no preloading, amount of preload compression being less than twice the amplitude, and amount of preload compression being more than twice the amplitude, respectively. 


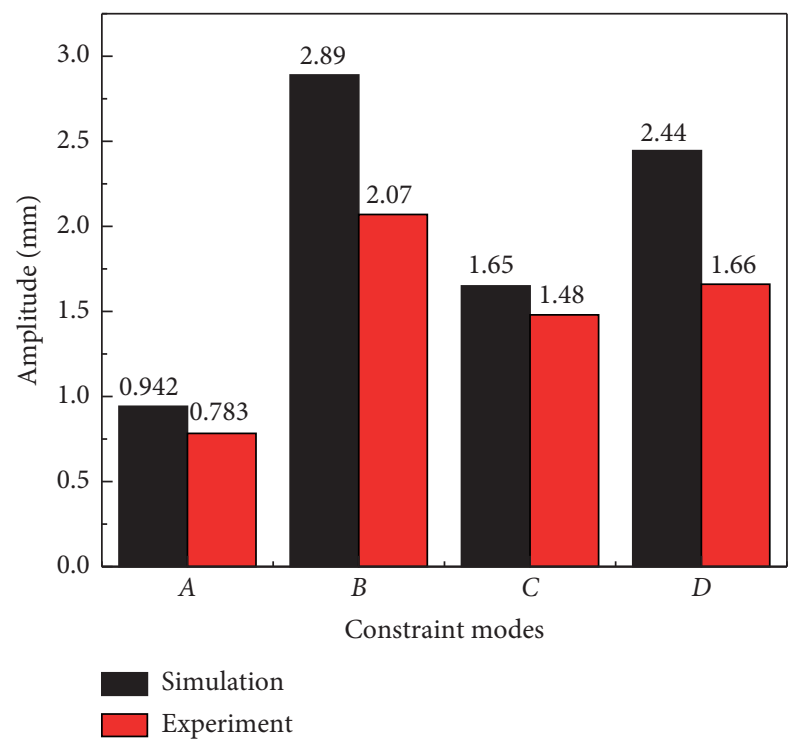

(a)

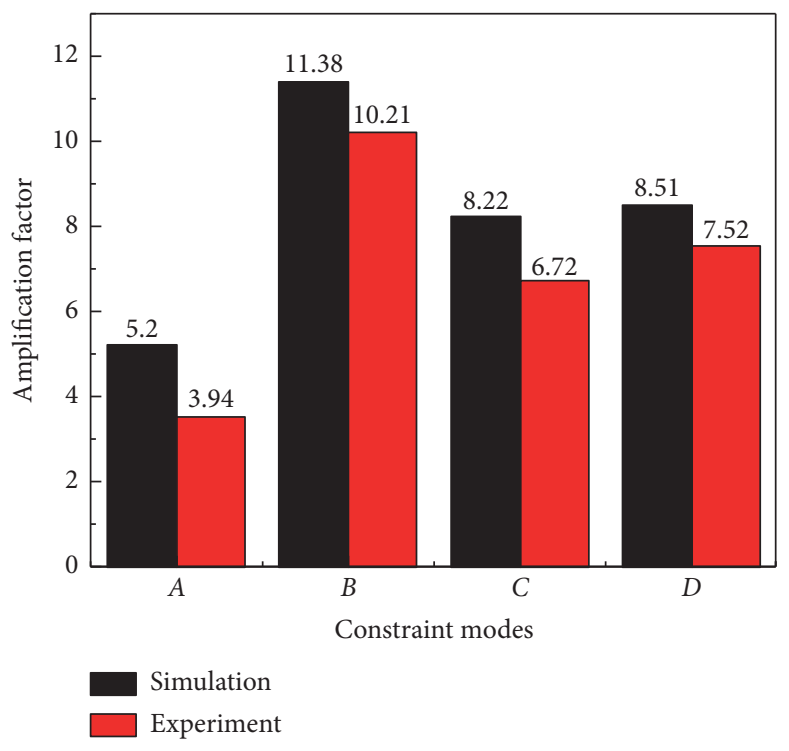

(b)

Figure 8: Amplitude and amplification factor of disc spring system with 10 springs under different constraint modes: (a) amplitude and (b) amplification factor. $A, B, C$, and $D$ refer to no locking and no preloading, locking and no preloading, amount of preload compression being less than twice the amplitude, and amount of preload compression being more than twice the amplitude, respectively.

system is 10.21 . These indicate the locking and no preloading is the best constraint mode among four different constraint modes.

Comparing the amplitude results in simulation and experiment, from Figure 8(a), it can be seen that the results in simulation are slightly larger than that in experiment. There are two reasons for this phenomenon: it can be seen from Figure 7(a) that the natural frequency in simulation is higher than that in experiment. According to formulas (4) and (5), the higher frequency means larger exciting force. The corresponding amplitude is larger. In addition, experimental interfering factors like energy loss during transmission, inefficiency of motor working, and test system error will lead to the results that the experiment outcomes are slightly less than simulation outcomes. However, amplitude of experiment and simulation are basically consistent.

4.3. Effects of the Numbers of Disc Springs. Figure 9(a) shows the amplitudes of the disc spring system under different number disc springs, and Figure 9(b) shows the corresponding amplification factors.

It can be seen in Figure 9(a) that, with the number of disc springs increasing, the amplitude of disc spring system first increases and then decreases in both simulation and experiment. The maximum amplitude $(2.11 \mathrm{~mm}$ in experiment) of the disc spring system appears at eight disc springs. Meanwhile, the amplitude of the disc spring system at ten disc springs is close to that at eight disc springs.

In addition, the amplification factor increases with the number of disc springs increasing in both simulation and experiment as shown in Figure 9(b), which indicates that better amplification effect can be obtained with more disc spring numbers. The maximum amplification factor (10.21 in experiment) of disc spring system appears at 10 disc springs.

When the excitation frequency is equal to the natural frequency, amplification factor in formula (7) can be simplified as

$$
|H(\omega)|=\frac{1}{\sqrt{2} \xi} .
$$

From formula (8), it can be seen that the amplification factor $H(\omega)$ is inversely proportional to the damping factor $\xi$. Meanwhile, the amplification factor increases with number of disc springs increasing, shown in Figure 9(b). This means that the corresponding damping of disc spring system decreases with number of disc springs increasing. Therefore, the damping of disc spring system can be reduced by increasing the disc spring numbers; thus, the corresponding amplification factor can be improved. It can be seen that the amplitude and amplification factor in simulation are slightly larger than that in experiment. The reasons are the same as explained in Section 4.2.

In order to investigate the optimum locking height of disc springs, the heights of disc springs under different numbers of disc springs before and after locking are recorded in Figure 10(a). It can be seen from Figure 10(a) that the heights of disc springs become smaller after locking. In order to more clearly display the height difference before and after locking, Figure 10(b) shows the height differences before and after locking under different numbers of disc springs. The height differences before and after locking refer to the compression amount in practical engineering application. It can be seen from Figure 10(b) that as the number of disc spring increases, the height differences before and after locking are all close to $3 \mathrm{~mm}$. The height differences under different number of disc springs have good consistency. This 


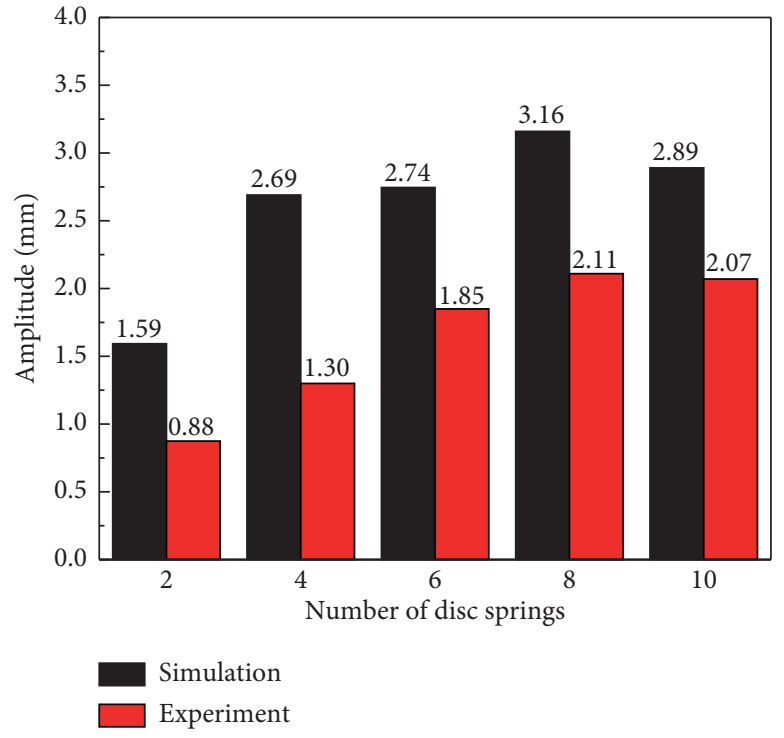

(a)

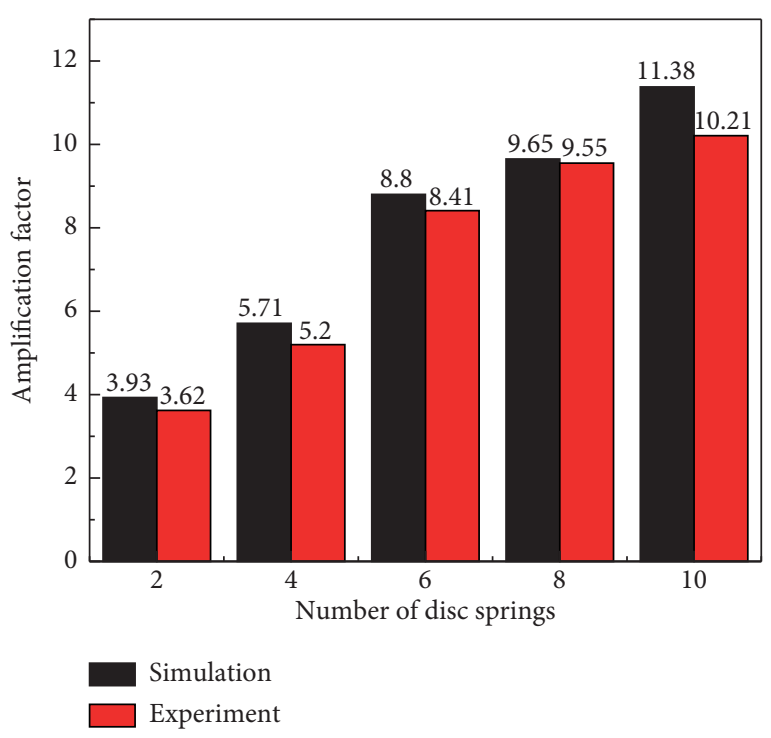

(b)

FIgUre 9: Amplitude and amplification factor of disc spring system in constraint of locking and no preloading under different numbers of disc springs.

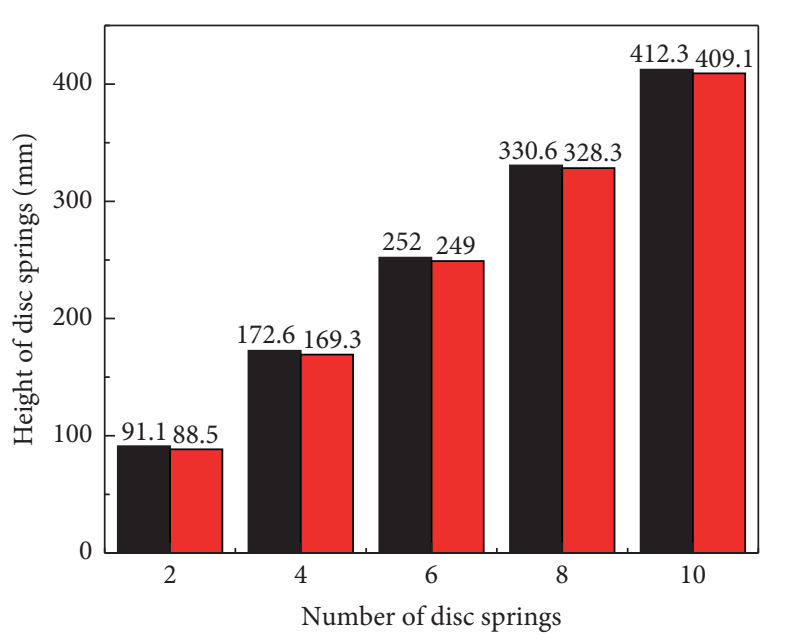

Before locking

After locking

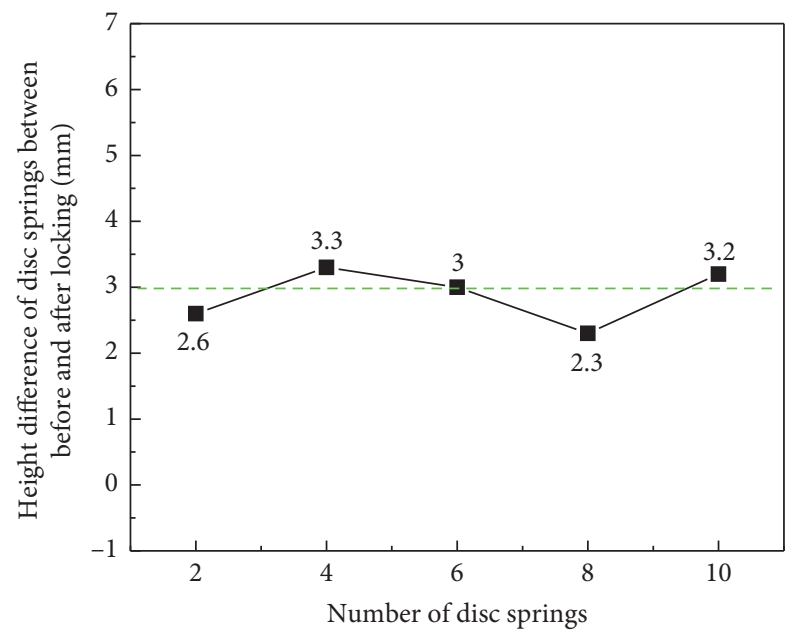

(b)

FIGURE 10: Height of the disc spring system before and after preloading in the constraint mode of locking and no preloading under different numbers of disc springs.

result provides a reference for the disc spring assembly in industrial production.

\section{Conclusion}

In this work, the influence of constraint modes and number of disc springs on the dynamic characteristics of the disc spring system is researched. By establishing the theoretical model of the disc spring system, the movement processes of the disc spring system under four different constraint modes are analyzed. Based on the results of dynamic analysis in simulation and experiment, it can draw the following conclusions.

(1) By studying the variation of stiffness and frequency under different constraint modes and different numbers of disc springs in the disc spring system, it is found that as the constraint modes change from $A$ to $D$, the natural frequency of the disc spring system increases, which indicates that the stiffness increases with the constraint modes changing from $A$ to $D$. Meanwhile, the natural frequency of the disc spring system decreases with the increase of the numbers of 
the disc spring, which suggests that stiffness decreases with the increase of disc spring numbers.

(2) Moreover, the amplitudes and amplification factors of the disc spring system are studied under different constraint modes. The results show that the maximum amplitude and amplification factor both appear at the constraint modes of locking and no preloading. These indicate that the locking and no preloading is the best constraint mode among the four different constraint modes.

(3) In addition, the amplitude of the disc spring system first increases and then decreases with the number of disc springs increasing, while the amplification factor increases with the number of disc springs increasing. The maximum amplification factor (10.21 in experiment) of the disc spring system appears at 10 disc springs. By studying the relationship between the number of disc springs and amplification factor and damping, we find that the damping of disc spring system can be reduced by increasing the disc spring numbers, and thus, the corresponding amplification factor can be improved.

(4) Furthermore, the heights of disc springs under different numbers of disc springs before and after locking are recorded. The result shows that as the number of disc spring increases, the height differences before and after locking are all close to $3 \mathrm{~mm}$, which indicates that the amount of locking compression in the assembly process has a good consistency when the number of disc springs changes.

The aforementioned conclusions can provide guidance for the design and application of elastic components on the vibration screen.

\section{Data Availability}

The data used to support the findings of this study are available from the corresponding author upon request.

\section{Conflicts of Interest}

The authors declare that they have no conflicts of interest.

\section{Authors' Contributions}

Jiacheng Zhou designed and conducted the simulation and experiment and wrote the first draft of the article. Chuzhe Zhang conducted the experimental analyses. Ziqiu Wang contributed to the systematic review of the literature and data retrieval and extraction. Kuanmin Mao conceived and analyzed the data and drafted the article. Xiaoyu Wang funded this research and provided all the experimental devices.

\section{Acknowledgments}

This work was partially supported by the National Natural Science Foundation of China under grant no. U19A2072.

\section{References}

[1] C. Du, K. Gao, J. Li, and H. Jiang, "Dynamics behavior research on variable linear vibration screen with flexible screen face," Advances in Mechanical Engineering, vol. 6, p. 957140, 2014.

[2] A. Kammerer and R. S. Abhari, "Experimental study on impeller blade vibration during resonance: part 2-blade damping," Structures and Dynamics, Parts A and B, vol. 5, 2008.

[3] L. Zhao, Y. Zhao, C. Bao, Q. Hou, and A. Yu, "Laboratoryscale validation of a DEM model of screening processes with circular vibration," Powder Technology, vol. 303, pp. 269-277, 2016.

[4] K. J. Dong, A. B. Yu, and I. Brake, "DEM simulation of particle flow on a multi-deck banana screen," Minerals Engineering, vol. 22, no. 11, pp. 910-920, 2009.

[5] M. L. Chandravanshi and A. K. Mukhopadhyay, "Analysis of variations in vibration behavior of vibratory feeder due to change in stiffness of helical springs using FEM and EMA methods," Journal of the Brazilian Society of Mechanical Sciences and Engineering, vol. 39, no. 9, pp. 3343-3362, 2017.

[6] Z. Yue-min, L. Chu-sheng, H. Xiao-mei, Z. Cheng-yong, W. Yi-bin, and R. Zi-ting, "Dynamic design theory and application of large vibrating screen," Procedia Earth and Planetary Science, vol. 1, no. 1, pp. 776-784, 2009.

[7] L. I. Slepyan and V. I. Slepyan, "Coupled mode parametric resonance in a vibrating screen model," Mechanical Systems and Signal Processing, vol. 43, no. 1-2, pp. 295-304, 2014.

[8] J. N. Eiras, J. Monzó, J. Payá, T. Kundu, and J. S. Popovics, "Non-classical nonlinear feature extraction from standard resonance vibration data for damage detection," The Journal of the Acoustical Society of America, vol. 135, no. 2, pp. EL82-EL87, 2014.

[9] S. J. Zhu, Y. F. Zheng, and Y. M. Fu, "Analysis of non-linear dynamics of a two-degree-of-freedom vibration system with non-linear damping and non-linear spring," Journal of Sound and Vibration, vol. 271, no. 1-2, pp. 15-24, 2004.

[10] W. Shan, M. Liu, and S. Wu, "Modal analysis and research of invalidation for light-duty resonance screen," Coal Mine Machinery (China), vol. 37, no. 5, pp. 35-37.

[11] J. Zhou, C. Zhang, Z. Wang, and K. Mao, "Study on dynamic characteristics of the disc spring system in vibration screen," Shock and Vibration, vol. 2020, Article ID 3518037, 12 pages, 2020.

[12] L.-p. Peng, C.-s. Liu, J. Li, and H. Wang, "Static-deformation based fault diagnosis for damping spring of large vibrating screen," Journal of Central South University, vol. 21, no. 4, pp. 1313-1321, 2014.

[13] C. K. H. Dharan and J. A. Bauman, "Composite disc springs," Composites Part A: Applied Science and Manufacturing, vol. 38, no. 12, pp. 2511-2516, 2007.

[14] S. Kitamura, S. Okamura, and K. Takahashi, "Experimental study on vertical component seismic isolation system with coned disk spring," Seismic Engineering, vol. 8, 2005.

[15] A. K. Samantaray, "Modeling and analysis of preloaded liquid spring/damper shock absorbers," Simulation Modelling Practice and Theory, vol. 17, no. 1, pp. 309-325, 2009.

[16] N. Yoshida, S. Kobayashi, I. Suetomi, and K. Miura, "Equivalent linear method considering frequency dependent characteristics of stiffness and damping," Soil Dynamics and Earthquake Engineering, vol. 22, no. 3, pp. 205-222, 2002.

[17] S. Y. Chen, M. S. Ju, and Y. G. Tsuei, "Estimation of mass, stiffness and damping matrices from frequency response 
functions," Journal of Vibration and Acoustics, vol. 118, no. 1, pp. 78-82, 1996.

[18] G. Wang and X. Tong, "Screening efficiency and screen length of a linear vibrating screen using DEM 3D simulation," Mining Science and Technology (China), vol. 21, no. 3, pp. 451-455, 2011.

[19] W. Sikora, K. Michalczyk, and T. Machniewicz, "A study of the preload force in metal-elastomer torsion springs," Acta Mechanica et Automatica, vol. 10, no. 4, pp. 300-305, 2016.

[20] J.-X. Yan, Q.-Z. Li, L.-G. Liu, and S.-H. Qian, "Optimal design of large circular vibrating screen based on multiple frequencies constraints and analytical sensitivity methods," The Open Mechanical Engineering Journal, vol. 8, no. 1, pp. 469474, 2014.

[21] G. Q. Lin and D. Shi, "Design and analysis of disc spring group in hydraulic tightener," Modern Manufacturing Engineering (China), vol. 8, no. 8, pp. 130-136, 2020.

[22] D. Shi and G. Q. Lin, "The design and finite element analysis of disc spring group in the hydraulic-casale sealing clamp device based on ANSYS," Chinese Hydraulics \& Pneumatics, vol. 10, no. 10, pp. 84-89, 2020.

[23] D. Zhu, S. D. Rajan, B. Mobasher, A. Peled, and M. Mignolet, "Modal analysis of a servo-hydraulic high speed machine and its application to dynamic tensile testing at an intermediate strain rate," Experimental Mechanics, vol. 51, no. 8, pp. 1347-1363, 2011.

[24] E. Antonino-Daviu, M. Fabres, M. Ferrando-Bataller, and V. M. R. Penarrocha, "Modal analysis and design of bandnotched UWB planar monopole antennas," IEEE Transactions on Antennas and Propagation, vol. 58, no. 5, pp. 1457-1467, 2010.

[25] J. H. Lee and B. S. Lee, "Modal analysis of carbon nanotubes and nanocones using fem," Computational Materials Science, vol. 51, no. 1, pp. 0-42, 2012.

[26] L. F. Ramos, L. Marques, P. B. Lourenço, G. De Roeck, A. Campos-Costa, and J. Roque, "Monitoring historical masonry structures with operational modal analysis: two case studies," Mechanical Systems and Signal Processing, vol. 24, no. 5, pp. 1291-1305, 2010.

[27] S. Kong, S. Zhou, Z. Nie, and K. Wang, "The size-dependent natural frequency of Bernoulli-Euler micro-beams," International Journal of Engineering Science, vol. 46, no. 5, pp. 427-437, 2008.

[28] H. Okamoto, D. Ito, K. Onomitsu et al., "Vibration amplification, damping, and self-oscillations in micromechanical resonators induced by optomechanical coupling through carrier excitation," Physical Review Letters, vol. 106, 2011.

[29] L.-p. Peng, C.-s. Liu, B.-c. Song, J.-d. Wu, and S. Wang, "Improvement for design of beam structures in large vibrating screen considering bending and random vibration," Journal of Central South University, vol. 22, no. 9, pp. 3380-3388, 2015.

[30] L. Dahmani, A. Khennane, and S. Kaci, "Crack identification in reinforced concrete beams using ANSYS software," Strength of Materials, vol. 42, no. 2, pp. 232-240, 2010.

[31] K. Mao, M. Zhu, W. Xiao, and B. Li, "A method of using turning process excitation to determine dynamic cutting coefficients," International Journal of Machine Tools and Manufacture, vol. 87, pp. 49-60, 2014.

[32] M. Hagiwara, K. Nishimura, and H. Akagi, "A mediumvoltage motor drive with a modular multilevel PWM inverter," IEEE Transactions on Power Electronics, vol. 25, no. 7, pp. 1786-1799, 2010.
[33] Y. F. Shu and Y. F. Zheng, "Transient dynamics analysis of the reachstacker speader based on ANSYS," Advanced Materials Research, vol. 5, pp. 212-215, 2015.

[34] S.-K. Kim, J.-H. Jeon, C.-H. Cho, E.-S. Kim, and J.-B. Ahn, "Modeling and simulation of a grid-connected PV generation system for electromagnetic transient analysis," Solar Energy, vol. 83, no. 5, pp. 664-678, 2009.

[35] J. Gao, Study on Disc Spring-High Damping Rubber Isolation Bearing, Beijing University of Technology, Beijing, China, 2018.

[36] N. A. Ubaidillah, K. Hudha, and F. A. A. Kadir, "Modelling, characterisation and force tracking control of a magnetorheological damper under harmonic excitation," International Journal of Modelling, Identification and Control, vol. 13, no. 1/ 2, pp. 9-21, 2011.

[37] W. Wang, X. Wang, and A. Li, "Coned disc spring compound vertical isolation: testing and modelling," Journal of Earthquake Engineering, pp. 1-33, 2020. 